\title{
O BIODIESEL COMO ELEMENTO DE DESENVOLVIMENTO SUSTENTÁVEL NO SEMI-ÁRIDO POTIGUAR
}

\author{
Valdemberg M. do N. Pessoa \\ Professor do Departamento de Indústria e Meio Ambiente do CEFET-RN (UNED- \\ Mossoró) ${ }^{1}$ \\ bergpessoa@cefetrn.br
}

Francisco das Chagas Silva Souza ${ }^{1}$

franciscosouza@cefetrn.br

Igor Guedes Rebouças

igorguedes_0@hotmail.com

\section{RESUMO}

A crescente preocupação mundial com o meio ambiente e com as desigualdades sociais advindas do atual modelo de desenvolvimento, baseado no uso, em larga escala, de combustíveis fósseis, principalmente o petróleo, desembocam em uma proposta de desenvolvimento que tenha como meta a sustentabilidade sócio-econômica e ambiental. A produção de energia por meio de biocombustíveis no intuito de reverter, em parte, o processo de degradação em que se encontra o planeta, apresenta-se como uma das alternativas viáveis na atualidade, despontando como vetor maior desse processo a agricultura energética, promotora de mudanças recentes no quadro da agricultura familiar do país. As discussões sobre biodiesel no Brasil têm priorizado as oleaginosas que venham a gerar maior emprego de mão-de-obra e que possam incluir regiões que estão à margem do processo de desenvolvimento econômico. Neste contexto, destaca-se a região nordeste do país como potencial produtora de biodiesel, introduzindo nesse processo os assentamentos de reforma agrária da região semi-árida. O trabalho aqui desenvolvido tem como objetivo central discutir a viabilidade da produção de oleaginosas para fins de biocombustível como elemento propulsor de desenvolvimento sustentável no semi-árido potiguar. Para tanto, será desenvolvida uma pesquisa de campo em assentamentos de reforma agrária, que se dará numa segunda etapa da pesquisa. No momento foi efetuada pesquisa bibliográfica para composição do marco teórico, que se reflete na elaboração do artigo ora apresentado. A pesquisa em questão faz parte do Núcleo de Estudos de Ciências e Tecnologias Ambientais (NECTA), dentro da temática Energia e Sustentabilidade, do Centro Federal de Educação Tecnológica do Rio Grande do Norte - CEFET/RN.

Palavras-chave: biocombustíveis, energia, sustentabilidade, semi-árido. 


\section{O BIODIESEL COMO ELEMENTO DE DESENVOLVIMENTO SUSTENTÁVEL NO SEMI-ÁRIDO POTIGUAR}

\section{INTRODUÇÃO}

Recentemente o Painel Intergovernamental de Mudanças Climáticas (IPCC), grupo de cientistas reunidos pela ONU, divulgou relatório apontando os danos causados pelo aumento da temperatura do planeta e estima as tragédias que vão ocorrer se não houver uma redução significativa nas emissões de gases causadores de efeito estufa. O principal deles é o CO2, resultado da queima de combustíveis fósseis. Dessa forma, os derivados de petróleo deverão ser substituídos por formas limpas de energias. Os biocombustíveis são apontados como uma alternativa que se torna cada vez mais forte e concreta.

A publicação do relatório do IPCC fez com que as atenções mundiais se voltassem para o Brasil, considerando que o nosso país possui mais de 30 anos de experiência com o etanol e extensas áreas agricultáveis para o plantio de oleaginosas, matéria-prima para o biodiesel. Hoje, segundo Girardi (2007, pp. 36-37), o Brasil produz cerca de 16 bilhões de litros de álcool por ano, em quase 3 milhões de hectares, suficiente para atender a $40 \%$ da frota de veículos nacionais. Segundo a Empresa Brasileira de Pesquisa Agropecuária (EMBRAPA), o Brasil possui cerca de 90 milhões de hectares de área disponível para a expansão da agricultura.

Com relação ao biodiesel, o Brasil poderá repetir a façanha que teve com a conversão da cana-de-açúcar em etanol. Há ainda vantagem para esse biocombustível: ele pode ser obtido a partir de uma multiplicidade de matérias-primas, tais como o dendê, a mamona, o algodão, a soja e o pinhão-manso.

O biodiesel, mesmo não sendo exclusividade da agricultura familiar, pode se tornar um mecanismo de geração de emprego e renda de pequenos agricultores familiares. Conforme Caetano (2006), em apenas dois anos de existência do programa nacional para o combustível, já havia 17 empresas envolvidas em 28 projetos no setor, além de 30 mil agricultores envolvidos, com a previsão de aumentar substancialmente esse número nos próximos anos. Para ela, com esse tipo de parceria, os agricultores familiares envolvidos no segmento do biodiesel conseguem uma boa relação custo-benefício, pois eles passam a investir menos em fertilizantes e defensivos, e mais em sementes e boa técnicas de cultivo.

A questão maior que permeia o contexto dos combustíveis alternativos, como é o caso do biodiesel, é a questão da energia. Países em desenvolvimento e países ricos necessitam desse insumo, pois nenhum país se desenvolve prescindindo de energia. Isso gera discussões científicas sobre um novo conceito, o da agroenergia, que, em síntese, representa a capacidade que sistemas agroindustriais têm de prover energia de forma renovável.

A bioenergia provavelmente tornar-se-á a matéria-prima base de todo um sistema produtivo em função de sua possível sustentabilidade. E o Brasil tem destaque por ser um país tropical que apresenta um elevado potencial para a produção de energia por meio de biomassa. 
As motivações de demanda por combustíveis no mundo sofrem profundas transformações. A sustentabilidade é o elemento decisivo na atualidade. Essa mudança é motivada, em parte pelo aquecimento global, sob o aspecto de emissões de gases de efeito estufa, intimamente ligadas à queima de combustíveis fósseis, e por outro lado, em virtude do prenúncio do declínio, em um futuro bem próximo, da exploração do petróleo.

As energias renováveis dos trópicos anunciam novas perspectivas para países pobres e em desenvolvimento, e ainda possibilitam se vislumbrar a desejada sustentabilidade energética para países ricos.

Esse trabalho faz parte de um projeto de pesquisa do programa de iniciação científica do CEFET-RN, em desenvolvimento no Núcleo de Estudos de Ciências e Tecnologias Ambientais (NECTA), na unidade descentralizada de Mossoró, tendo como objetivo discutir a viabilidade da produção de oleaginosas para fins de biocombustível como elemento propulsor de desenvolvimento sustentável no semi-árido do Rio Grande do Norte.

A pesquisa está ainda em andamento, tendo sido concluída a fase de revisão de literatura, a qual será apresentada a seguir. Posteriormente, será desenvolvida uma pesquisa de campo em assentamentos de reforma agrária, com o objetivo de fazer um estudo comparativo entre aqueles que estão envolvidos com a produção de oleaginosas e outros que ainda não conhecem essa produção.

\section{A AGROENERGIA E SEUS DESDOBRAMENTOS SÓCIO-AMBIENTAIS}

\subsection{A Produção do Biodiesel e a Sustentabilidade Ambiental}

Foi a partir da invenção do motor a diesel, pelo engenheiro francês de origem alemã Rudolph Christian Carl Diesel (1858-1913) no final do século XIX, que se vislumbrou, pela primeira vez, a possibilidade de se usar óleos vegetais como combustível. Foi apenas na primeira década do século passado que o óleo diesel passou a ser produzido a partir do petróleo. A primeira patente de biodiesel feito com óleo de amendoim e metanol foi depositada no Japão na década de 1940, seguida de outras três patentes americanas na década de 1950. (BATISTA, 2007)

No Brasil, as pesquisas só tiveram início na década de 80 do século XX, e o responsável pela primeira patente brasileira de um processo de biodiesel, foi o professor Expedito Parente, da Universidade Federal do Ceará (UFC), o qual produziu o combustível a partir de uma mistura de óleo de mamona e metanol.

O biodiesel pode ser produzido a partir de diversas matérias-primas, tais como óleos vegetais, gorduras animais, óleos e gorduras residuais, por meio de diversos processos. Pode também ser usado puro ou em mistura de diversas proporções com o diesel mineral.

Para converter óleos vegetais em biocombustíveis e seus derivados, o processo predominante é a transesterificação em meio alcalino, onde se reagem triglicérides com um álcool, etanol ou metanol, produzindo glicerina e ésteres dos ácidos graxos componentes do óleo vegetal. A diversidade de matérias-primas, óleos, e as alternativas de processo levam a diversos programas de pesquisa e desenvolvimento tecnológico na atualidade. 
O uso do metanol, um álcool tóxico proveniente do petróleo, é uma das maiores desvantagens desse processo. Uma alternativa interessante seria a utilização do etanol, álcool etílico, obtido da cana-de-açúcar, que é renovável e possui maior segurança no manuseio devido a sua menor toxicidade. Além disso, no Brasil existe grande disponibilidade de álcool de cana, sendo o maior produtor mundial de etanol, enquanto o metanol consumido no país para outras finalidades, tem quase metade de seu volume importado.

Hoje, a base da matriz energética não renovável do Brasil é o petróleo com 43,1\% e o óleo diesel, a matriz dos combustíveis líquidos, com 57,9\%, havendo destes, 10\% de dependência externa. Assim, o biodiesel passa a ser do ponto de vista econômico a oportunidade de substituição das importações pela possibilidade de exportação viabilizada inicialmente através do grão da mamona que possui 75\% de óleo extraível, podendo assim contribuir de forma direta e expressiva para a independência energética brasileira. (PIASSI, 2007)

Quanto às matérias-primas mais promissoras para utilização, deve-se referir aos estudos recentes da EMBRAPA, em 2003, para levantar os cultivos e as aptidões regionais. De uma forma geral, tem sido mencionada a soja para as regiões Sul, Sudeste e Centro-Oeste, a mamona para o Nordeste e o dendê para a região Amazônica. Girassol, amendoim e outros também têm sido considerados. Igualmente, as palmáceas tropicais são sempre mencionadas como viáveis e potenciais produtoras de biodiesel. Alguns estudos apontam perspectivas interessantes para as oleaginosas aparentemente inusitadas e pouco citadas, como o abacate, com uma produtividade estimada em 1.200 litros de biodiesel por hectare.

Aliado ao desenvolvimento de tecnologias mais adequadas em relação à produção de biodiesel, existem pesquisas, como por exemplo, a do Núcleo Interdisciplinar de Planejamento Energético da Unicamp, em São Paulo, que desenvolve estudos relativos à expansão da produção de álcool no Brasil de maneira a substituir $10 \%$ da gasolina no mundo até 2025. Portanto, o etanol, produzido da cana de açúcar, possui hoje importância quando analisamos a sua cadeia produtiva, em função da substituição da gasolina, importante derivado do petróleo, e também como agente fundamental para a produção de biodiesel, que especialistas anunciam ser o substituto do diesel.

No entanto, o desenvolvimento genético e os processos de produção de muitas das opções para o biodiesel ainda não possuem caráter de amadurecimento, do ponto de vista das tecnologias empregadas e conseqüências ao meio ambiente, como é a cadeia do etanol produzido da cana de açúcar, com exceção, possivelmente, ao biodiesel produzido da soja, que já teve sua curva de aprendizado percorrida e muito provavelmente não mais reduzirá satisfatoriamente seus custos de produção.

\subsection{Energia: Fator Essencial para o Desenvolvimento Sustentável}

Por um longo período da história das civilizações modernas, o crescimento econômico foi feito às custas da devastação ambiental ou degradação social, onde se imaginava que os fins justificavam os meios. Vivenciamos essa situação tempo suficiente para que essa visão passasse a ser estabelecida como consenso geral. Até pouco tempo, era consenso também, que o processo de industrialização traria benefícios para todos, e os possíveis impactos negativos sobre o meio ambiente, advindos da atividade industrial, não eram considerados 
prioritários. Esse paradigma começou a ruir, ainda que lentamente, desde o final do século passado.

Entretanto, o modelo de desenvolvimento dos países ricos ainda serve de padrão para os países pobres. Para alcançar esse patamar, os não-industrializados necessitam de um insumo potencial: energia. Para tanto, têm que recorrer aos recursos naturais para que essa energia necessária ao desenvolvimento seja produzida. Lembremos que nenhum país se desenvolve prescindindo de energia, chegando aos extremos de serem gerados sangrentos conflitos e guerras infindáveis para a sua obtenção.

Daí surge toda uma concepção que relaciona desenvolvimento e sustentabilidade, levando a comunidade internacional a se preocupar com os limites do progresso industrial do planeta. Por volta dos anos 60, surgiram as primeiras discussões sobre os riscos da degradação do meio ambiente e da capacidade limitada da Terra em absorver as intervenções do homem com seus processos de produção crescentes. Essas discussões ganharam tanta intensidade que levaram a Organização das Nações Unidas - ONU - em 1972, a promover a Conferência sobre Meio Ambiente Humano, em Estocolmo. Significa dizer que não estamos discutindo essas questões há tanto tempo assim, que o tema possui maior destaque há pouco mais de três décadas, mas que existe uma preocupação em mudar o contexto que envolve as questões ambientais. Mas se essa preocupação é real, é preciso pensar em mudar os sistemas produtivos e rever o modelo de desenvolvimento atual do mundo industrializado moderno.

Esse contexto de insustentabilidade está intimamente relacionado à utilização de combustíveis fósseis como base da matriz energética mundial, o que define, de certa forma, a geopolítica no mundo. $\mathrm{O}$ atual panorama energético mundial, de acordo com o Ministério da Agricultura, Pecuária e Abastecimento (MAPA), mostra uma participação total de $80 \%$ de fontes não renováveis de energia, sendo 36\% de petróleo, 23\% de carvão e $21 \%$ de gás natural, longe de ser um adequado modelo de desenvolvimento sustentável.

As mudanças provenientes da utilização de melhores recursos tecnológicos ou as revisões efetuadas nas políticas ambientais, que avançam ainda timidamente, não podem ser consideradas como as únicas bases para o desenvolvimento sustentável. A maneira como produzimos em nossa economia globalizada acarreta uma desigualdade social e acaba por determinar, de certa forma, a inviabilidade de se alcançar um processo de desenvolvimento capaz de conservar o meio ambiente e, ainda assim, obtermos progresso no sentido de proporcionar condições mais dignas de vida às pessoas de um modo geral.

Dentre as fontes de energia não-renováveis, nesse contexto, destaca-se o petróleo, que é base da economia no mundo, e desde sua descoberta em Lousiana, nos Estados Unidos, em 1859, seu uso disseminou-se pelo planeta, tornando-o imprescindível para as sociedades industrializadas. Existia a crença de que o petróleo nunca iria acabar, fato que está sendo contestado já há algum tempo e vem sendo objeto de estudos de muitos cientistas. Seu fim estimado dificilmente será alcançado, pois seu custo se tornará proibitivo, ou seja, deixará de ser competitivo em relação às outras fontes de energia.

A mudança anunciada na matriz energética mundial, em virtude da diminuição progressiva da exploração de petróleo, abre uma ampla discussão de como será a era da energia renovável e quem determinará o rumo dessa história. Daí emerge inúmeras discussões científicas sobre um novo conceito, o da agroenergia, ou bioenergia, que, em síntese, 
representa a capacidade que sistemas agroindustriais têm de prover energia de forma renovável.

Assim, a bioenergia provavelmente tornar-se-á a matéria-prima base de todo um sistema produtivo em função de sua possível sustentabilidade. O Brasil se destaca nesse cenário pela sua elevada participação de fontes renováveis em sua matriz energética, fato este explicado, em primeiro lugar, pelas condições naturais, como, por exemplo, as bacias hidrográficas para produção de eletricidade, e em segundo lugar, por ser um país tropical que apresenta um elevado potencial para a produção de energia por meio de biomassa.

Existem inúmeras teorias que levantam a possibilidade de substituição do petróleo por biocombustíveis, o que mudaria completamente a geopolítica mundial. De certa forma isso já é uma realidade atual, ainda modesta e introdutória, mas em franca ascensão. Contudo, para que uma nova matriz energética mundial realmente venha a preservar a vida e o bemestar dos indivíduos no planeta faz-se necessária uma profunda transformação nos padrões atuais de produção e consumo, no estilo de vida das pessoas, e que se repense o conceito de desenvolvimento atual e da própria organização das sociedades.

A abundância das energias renováveis em países tropicais como o Brasil e em outras partes do mundo, anuncia novas perspectivas para os países pobres e em desenvolvimento, e ainda possibilita se vislumbrar uma possível sustentabilidade energética para os países ricos. Mas estas novas formas de energia não podem servir para a manutenção do quadro atual, com a permanência das diferenças sócio-econômicas que vigoram no mundo inteiro.

Nesse momento em que ainda tratamos questões ambientais como simples alertas, parte desse comportamento atribuído ao protecionismo gerado pelas cadeias produtivas atuais, vislumbram-se legítimas preocupações com o porvir da humanidade, que devem servir de base para as inúmeras discussões que permeiam as questões da qualidade de produção e sustentabilidade de processos produtivos, que acabam por desembocar no modelo de consumo que temos atualmente no mundo.

\subsection{Desenvolvimento Sustentável e Agroenergia}

Já está em gestação uma transformação nas motivações da demanda de combustíveis no mundo, cujo elemento decisivo será a sustentabilidade. Em grande parte, motivado pelo aquecimento global, sob o aspecto de emissões de gases de efeito estufa, intimamente ligadas a queima de combustíveis fósseis.

Uma outra abordagem, que se une a anterior, é a de que temos um processo de produção de petróleo crescente e que, segundo especialistas, atingirá seu clímax nos próximos 20 ou 30 anos, tendendo a não ser viável economicamente sua produção em larga escala na medida em que seu declínio avançar. Em entrevista a Veja, Colin J. Campbell, Ph.D. da Universidade de Oxford afirma:

Estamos vivendo o fim da primeira metade da era do petróleo. Ela durou 150 anos e permitiu uma rápida expansão da indústria, dos transportes, do comércio e da agricultura. A produção mundial aumentou seis vezes, enquanto a produção do petróleo também crescia. Agora, ela está também chegando ao pico e declinará de maneira irreversível. Começa, então, a segunda metade da era do 
petróleo, que acarretará o declínio de tudo o que depende do ouro negro. Isso quer dizer que o crescimento econômico como conhecemos hoje não será mais possível. O fim da primeira era do petróleo promete ser uma reviravolta de magnitude nunca vista. $O$ mundo nunca deparou com algo semelhante. (2005, p. 15)

Como podemos ver o petróleo não será mais, até o final desse século, a base energética no mundo. Entra em cena então a bioenergia.

Segundo Bittencourt (2005, p. 6) uma das questões presentes no debate atual sobre a agricultura é justamente a sustentabilidade. Nos desafios colocados pela sociedade aos sistemas de produção agropecuária estão incluídos os já conhecidos, relacionados à necessidade de produção de alimentos, fibras e outras matérias-primas em quantidade e qualidade adequadas e, também a nova exigência da sociedade de que essa produção não contamine o ambiente, não exerça pressão inadequada sobre os recursos naturais e que leve em consideração os aspectos relacionados à eqüidade social.

Em meio a esse cenário está à produção de biodiesel no Brasil, onde as discussões sobre o tema têm priorizado as oleaginosas que venham a gerar maior emprego de mão-de-obra e que possam estar incluindo regiões que estão à margem do processo de desenvolvimento econômico. Neste contexto, destaca-se a região nordeste como potencial produtora de biodiesel de mamona, em sua região semi-árida, em particular, podendo utilizar-se desta alternativa para incluir no processo agricultores familiares desprovidos de alternativas mais rentáveis.

Um dos maiores desafios e também uma das grandes motivações para a produção de biodiesel no Brasil são os benefícios sociais que esse novo combustível pode trazer. Estudos desenvolvidos pelo Ministério do Desenvolvimento Agrário (MDA), pelo Ministério da Agricultura, Pecuária e Abastecimento (MAPA), pelo Ministério da Integração Nacional (MIN) e pelo Ministério das Cidades (MC) mostram que a cada 1\% de substituição de óleo diesel por biodiesel produzido com a participação da agricultura familiar podem ser gerados cerca de 45 mil empregos no campo, com renda média anual de aproximadamente R\$ 4.900,00 por emprego. (SLUSZZ, 2006, p. 4)

Os princípios básicos orientadores das ações governamentais direcionadas ao biodiesel tendem a ser a inclusão social e o desenvolvimento regional, especificamente por meio da geração de emprego e de renda. Entretanto, para isso, destaca Sluszz (2006, p. 6) devem-se levar em conta os aspectos industrial, econômico, ambiental e social, sendo importante o aproveitamento das potencialidades e características específicas de cada região brasileira para produção desse combustível alternativo.

No nordeste brasileiro, o semi-árido tem destaque na produção de mamona, oleaginosa que possui características ideais para o plantio nessa região. Segundo informações colhidas no Portal do Biodiesel (2007), a mamona pode ser considerada a principal oleaginosa para produção de biodiesel, por ser de fácil cultivo, de baixo custo e por ter resistência à seca, adaptando-se muito bem a forte exposição ao sol, altas temperaturas, requerendo no mínimo $500 \mathrm{~mm}$ de chuvas para seu crescimento e desenvolvimento normal, sendo assim indicada para regiões semi-áridas. 
De acordo com o Pólo Nacional de Biocombustíveis - ESALQ/USP, no ano de 2006 a região Nordeste já despontava como a maior produtora de matéria-prima para a fabricação de biodiesel, com mais de $70 \%$ dos hectares plantados em todo o País, até o começo do segundo semestre daquele ano. Além de grande produtora de mamona, oleaginosa mais cultivada no Nordeste para a fabricação de biodiesel, essa região também desponta na comercialização do biocombustível. Dos 840 milhões de litros vendidos nos quatro leilões de biodiesel realizados pela Agência Nacional de Petróleo, Gás Natural e Biocombustíveis (ANP), 319 milhões de litros têm origem no Nordeste.

No Brasil, uma das principais preocupações com relação ao plantio de oleaginosas destinadas à produção de biodiesel, é saber se a cultura é sustentável em determinada região e se possibilita às famílias viverem dignamente, ou seja, se o plantio de biodiesel realmente vale a pena, não levando em consideração apenas à produção de oleaginosas como fonte de subsistência para agricultores familiares.

Enfatiza Sluszz (2006, p. 18), que ainda são incipientes as pesquisas de novas variedades e de tecnologias de manejo da mamona, o que faz com que em termos de inclusão social, caso os produtores não sejam preparados para enfrentar um ambiente competitivo, não suportem a concorrência da produção em novas áreas com tecnologias mais modernas e emprego de capital intensivo.

Até agora não há nenhum estudo aprofundado sobre as conseqüências e impactos ambientais da expansão das lavouras de plantas oleaginosas no semi-árido nordestino. Dessa forma, faz-se necessário uma análise mais aprofundada para as questões relacionadas à produção dessas oleaginosas para a agroenergia, pois nem todo avanço econômico e desenvolvimento podem ser considerados como progresso dentro de um contexto de desenvolvimento sustentável.

\subsection{O Biodiesel no Estado do Rio Grande do Norte}

A partir de 2008, a produção de biodiesel no Brasil tenderá a ser realizada com tecnologia $100 \%$ nacional. Para isso, duas usinas de produção experimental da Petrobras, localizadas em Guamaré, cidade litorânea do Rio Grande do Norte, estão em fase de testes com produção do óleo vegetal a partir de mamona, podendo ser ampliados para outras oleaginosas brasileiras, como o girassol, dendê (palma), amendoim, babaçu, pinhão manso e soja. Além disso, ambas podem utilizar etanol ou metanol como reagente no processo de produção.

As usinas fazem parte do Pólo de Guamaré, complexo industrial construído pela Petrobras para beneficiar óleo e o gás natural extraído dos campos marítimos de Ubarana e Agulha e dos campos terrestres de todo o estado. Em 2005, foi inaugurada a primeira Unidade Experimental de Biodiesel, a UEB-01, usando tecnologia convencional a partir de óleos vegetais, já a segunda, a UEB-02, inaugurada em 2006, é uma usina experimental que produz biodiesel a partir da tecnologia patenteada pela Petrobras, diretamente dos grãos das oleaginosas, sem a necessidade de processar o grão antes para a extração do óleo vegetal, tecnologia utilizada somente no Brasil. (OLIVEIRA, 2007)

No Rio Grande do Norte está sendo trabalhada a produção de biodiesel a partir da agricultura familiar. Isto é feito, também, para a obtenção do Selo Combustível Social, concedido pelo Governo Federal, que garante ao produtor de biodiesel direito a benefícios 
de políticas públicas específicas, voltadas para estimular a inclusão social de agricultores familiares na cadeia produtiva do biodiesel.

Assim, em assentamentos de reforma agrária espalhados pelo Estado, agricultores familiares que ganharam a terra para morar, normalmente possuíam cultivo de arroz, feijão e sorgo (importante cereal usado para alimentação animal), alimentos que eram usados somente como fonte de sobrevivência e subsistência, agora, em virtude do crescimento da demanda por combustíveis renováveis, esses mesmos agricultores, passaram a lidar com novas oportunidades, incentivados pelo programa de cultura de oleaginosas para produção de biodiesel do Estado, cuja meta para o ano de 2008, é atingir 20.000 hectares de área cultivada com girassol, mamona e algodão, beneficiando mais assentamentos rurais e comunidades de agricultores familiares.

\section{CONSIDERAÇÕES FINAIS}

\subsection{Relativas aos Impactos Ambientais}

A produção de biocombustíveis apesar de todas as vantagens mencionadas, apresenta alguns paradoxos. A forma como tem sido implantada pode desencadear, posteriormente, problemas sócio-ambientais irreversíveis. Poderíamos citar como exemplo o PROÁLCOOL, criado pelo governo brasileiro na década de 70 do século XX. Esse programa, mesmo que tenha reduzido as importações de petróleo em uma época de rápida elevação de seus preços no mercado internacional, no tocante à área agrícola, dado que o sistema predominante de cultivo da cana-de-açúcar é a monocultura, trouxe, dentre os principais impactos ambientais, os seguintes: efeitos no solo e nos rios em decorrência do uso de agrotóxicos; compactação do solo devido ao uso intensivo de máquinas agrícolas; erosão do solo; emissões de poluentes pela prática corrente de queimar a cana-de-açúcar antes da colheita; e empobrecimento da diversidade biológica (vegetal e animal) devido à eliminação de todos os seres vivos que, de uma forma ou de outra, estão associados à expansão da cana-de-açúcar. (GUARNIERI; JANNUZZI, 1992)

Na etapa do processamento industrial da cana-de-açúcar para a produção de álcool, os principais efluentes produzem uma carga de $8,7 \mathrm{~kg}$ de DBO (Demanda Bioquímica de Oxigênio) por tonelada de cana processada. A demanda bioquímica de oxigênio constitui uma medida do potencial de carga poluidora da matéria orgânica de efluentes. Quanto maior for a DBO, maior será a competição por oxigênio entre a matéria orgânica dos efluentes e os peixes e outros seres vivos nos rios que necessitam de oxigênio para viverem. Esta competição pode alcançar tal nível que, dependendo dos graus de concentração ela chega a inviabilizar a própria sobrevivência de peixes e de outros seres vivos. (GUARNIERI; JANNUZZI, 1992)

Fazendo uma análise paralela, diante do exposto em relação ao cultivo de cana-de-açúcar para a produção de energia, resta-nos questionar se o biodiesel não terá um destino semelhante. Alguns possíveis problemas já podem ser apontados: 1- a ascensão desse novo mercado é acompanhada pelo risco de aumentar a demanda por produtos de grande impactos na natureza. A expansão da soja, por exemplo, tem trazido graves problemas para a Amazônia. 2- Para serem produzidos, as oleaginosas necessitam de grande volume de combustível para mover os tratores e colheitadeiras, ou seja, contraditoriamente geram mais emissões de poluentes na atmosfera. 3- A produção é feita em larga escala e de 
caráter mono cultural. Sabe-se que as monoculturas trazem, entre outros danos, a alteração com perda do perfil do solo e da flora, com modificação dos recursos culturais. 4- As promessas de lucros geram o risco dessas culturas ocuparem o lugar dos alimentos nas prioridades do mercado, ou o aumento dos preços, o que resultaria também em desabastecimento. De acordo com Girardi (2007, p. 39), na China houve uma elevação dos preços dos grãos e do porco em função do avanço da produção de milho para a produção do etanol sobre as áreas antes destinadas às colheitas voltadas à alimentação humana e desses animais.

Além disso, os biocombustíveis estão sendo vistos como elemento indutor de desmatamentos e acusados de desrespeitar direitos trabalhistas básicos. Por esses motivos, por meio da Empresa Brasileira de Pesquisa Agropecuária (EMBRAPA), passarão a ter um sistema de indicadores de sustentabilidade específicos para gestão ambiental e certificação de sua produção. As avaliações de impacto incluirão indicadores como distribuição de renda, qualidade do emprego, segurança e saúde no trabalho, além de acesso à educação, serviços básicos, esporte e lazer. A análise será estendida a padrões de consumo, conservação dos habitats e do patrimônio histórico e artístico, entre outros.

Segundo Zanatta (2007) serão verificados 62 itens integrados em cinco dimensões, como ecologia (reserva legal), qualidade ambiental (atmosfera, água e solo), valores sociais, culturais e econômicos, além de gestão e administração. As mudanças nesses indicadores afetam o desenvolvimento local e a qualidade de vida das comunidades, com isso poderão ser estabelecidas conexões entre as avaliações de impactos ambientais e sua gestão sustentável para uma possível certificação.

\subsection{Relativas às Questões Sócio-políticas}

Um outro aspecto relevante são as questões sócio-políticas, que estão no entorno daquilo que se refere aos biocombustíveis, que ainda não se elucidaram por completo. Tendo em mente que a era dos combustíveis fósseis dominam a geopolítica atual, que obteve sua consolidação ao longo dos últimos 200 anos de história, deve-se inferir a dimensão da dificuldade de se estabelecer um novo panorama para um mundo moderno baseado em energias alternativas e renováveis. Dois séculos, como diz Vidal (2004), embora tivesse representado apenas breve intervalo da história da humanidade, em suas conseqüências erigiu-se em paradigma inexorável e único como modelo energético de desenvolvimento.

Continua Vidal (2004) em sua análise discorrendo que, enquanto essas formas energéticas renováveis - hidratos de carbono - exigem plantio, irrigação e colheita, em processo de produção incomparavelmente mais árduo e trabalhoso do que a energia concentrada nos combustíveis fósseis, estes resultam da transformação dos hidratos de carbono em hidrocarbonetos ao longo de centenas de milhões de anos em processo de fossilização. Disso resultam formas energéticas concentradoras, de reduzidas localizações no planeta, o que favorece a cobiça e o domínio pelo grande capital.

Sabe-se que as energias oriundas de combustíveis fósseis estão em franca depauperação, e que isso gera conflitos em virtude do vislumbre de seu término, onde nações com poderio econômico-militar tentam de forma brutal preservar para si o que resta das reservas em forte decréscimo. 
Diante desse quadro desastroso, Costa (2007) analisa que, muitos acreditam e manifestam a crença de que o mercado pode ser o responsável pela implantação da filosofia do desenvolvimento sustentável. Acreditam que, com o decorrer do tempo, e com o surgimento de novas tecnologias, os problemas ambientais podem ser sanados e superados, resultando numa melhoria do bem-estar social ou mesmo na diminuição das desigualdades sociais. De acordo com o modelo de desenvolvimento capitalista, com base no consumo pelo consumo, no militarismo e na da lógica de acumulação do capital, o planeta está sendo levado a uma situação catastrófica do ponto de vista do meio ambiente e das condições de sobrevivência de um modo geral, demonstrando ser improvável que se estabeleça o esperado desenvolvimento sustentável com a crença nos ditames do mercado.

A mudança do modelo de desenvolvimento atual torna-se exigência para que o mundo se desenvolva de forma a reordenar-se, o que perpassa a questão da energia em si. A discussão deverá ser mais ampla e abrangente. Sabe-se que, para se realizar o desenvolvimento sustentável, são necessários investimentos em alternativas renováveis de energia, mas Costa (2007) atenta que, discutir novas fontes de energia implica, em primeiro lugar, refletir a serviço de quem estará esta nova matriz, e levar em conta quem se beneficiará ou a qual propósito ela servirá. Ou seja, energia para quê? E para quem?

Assim, dentro do panorama energético atual, observa-se uma situação drástica, envolvendo países de importância como China e Alemanha, por exemplo, que necessitam de soluções energéticas renováveis, que possivelmente se encontram disponíveis somente nas condições naturais que o Brasil possui. Regiões tropicais espalhadas pelo restante do globo terrestre não desfrutam de extensas áreas territoriais para esse propósito, não possuem radiação solar abundante ou até mesmo de recursos hídricos suficientes, da forma que ocorre no continente brasileiro.

Levando-se em consideração todas essas questões, o modelo de produção de biocombustíveis que se prenuncia não pode trazer impactos negativos para possíveis fornecedores dessa energia renovável, não transformando países como o Brasil em um grande exportador de combustíveis líquidos não fossilizados, destinando grandes extensões de terra para a monocultura, para sustentar o atual sistema sócio-político mundial baseando-o em um novo vetor energético: a agroenergia.

\section{REFERÊNCIAS BIBLIOGRÁFICAS}

BATISTA, Antonio Carlos Ferreira. Biodiesel no tanque. Disponível em: <http://www.ambientebrasil.com.br/composer.php3?base=./energia/index.html\&conteudo= ./energia/artigos/oleo_vegetal.html>. Acesso em: 23 ago. 2007.

BITTENCOURT, Henrique Von Hertwig. A Matriz Energética no Desenvolvimento Sustentável de Pequenas Propriedades Rurais. Universidade Federal de Santa Catarina - UFSC, Centro de Ciências Agrárias, Curso de Agronomia, Relatório de Estágio de Conclusão de Curso, 2005.

BRASIL. Ministério da Agricultura, Pecuária e Abastecimento. Plano Nacional de Agroenergia. Disponível em: <http://www.agricultura.gov.br/pls/portal/docs/ PAGE/MAPA/PRINCIPAL/DOCUMENTOS/AGROENERGIA.PDF> Acesso em: 26 out. 2005. 
CAETANO, Mariana. O desafio do biodiesel. Globo Rural, São Paulo: Ed. Globo, n. 256, p. 40-48, nov. 2006.

CAMPBELL, Colin J. O fim do começo. Entrevistador: MARTINO, Victor. Veja, São Paulo: Abril, n. 40, v. 38. pp. 11-15.

CHÂTEAU, Bertrand. A vida depois do petróleo. Revista Scientific American Brasil, Especial Deter o Aquecimento, nº. 19, Editora Duetto, ago. 2007, pp. 46-51.

COSTA, Heitor Scalambrini. Etanol e biodiesel: energia pra quem?. Disponível em: <http://www.reporterbrasil.com.br/exibe.php?id=1116>. Acesso em: 15 jul. 2007.

GIBBS, W. Wayt. Plano B para a energia. Revista Scientific American Brasil, Especial Deter o Aquecimento, $n^{\circ}$. 19, Editora Duetto, ago. 2007, pp. 90-98.

GIRARDI, Giovana. O país do etanol. Horizonte geográfico, São Paulo: Ed. Horizonte, v. 20, n. 112, ago. 2007, pp. 32-41.

GUARNIERI, Laura C.; JANNUZZI, Rto de Martino. Proálcool: impactos ambientais. In: Revista Brasileira de Energia, v. 2, n. 2, 1992. Disponível em: <http://www.sbpe.org.br/v2n2/v2n2a7.htm> Acesso em: 01 set. 2007.

LEITE, Rogério Cezar de Cerqueira. Etanol, o melhor dos biocombustíveis. Revista Scientific American Brasil, Especial Deter o Aquecimento, $\mathrm{n}^{\circ}$. 19, Editora Duetto, ago. 2007, pp. 53-57.

OLIVEIRA, Tatiane. Biodiesel gera energia e renda no nordeste. Disponível em: <http://www.cenbio.org.br/pt/noticia_mostra.asp?id=2888>. Acesso em: 31 jul. 2007.

PIASSI, Maria Carolina. Combustível limpo para o transporte sustentável. Disponível em:

<http://www.ambientebrasil.com.br/composer.php3?base=./energia/index.html\&conteudo= ./energia/artigos/combustivel_transporte.html>. Acesso em: 23 jul. 2007.

POLOBIO. Biodiesel: Nordeste desponta como líder na produção de mamona. Disponível em: http://www.polobio.esalq.usp.br/noticiasvisualizar.php?Id=443\&PHPSESSID=21e217dbbd00b5918e58cba843d41cdf. Acesso em: 09 mai. 2007.

PORTAL DO BIODIESEL. Plantas. Disponível em: <http://www.biodieselbr.com/>. Acesso em: 07 jul. 2007.

SLUSZZ, Thaisy; MACHADO, João A. Dessimon. Características das Potenciais Culturas Matérias-Primas do Biodiesel e sua Adoção pela Agricultura Familiar. Sociedade Brasileira de Economia e Sociologia Rural. XLIV Congresso da Sober: “Questões Agrárias, Educação no Campo e Desenvolvimento”. Fortaleza - CE, 2006. 
VIDAL, José Walter Bautista. O Biodiesel e o Brasil. Disponível em: $<$ http://www.jornaldomeioambiente.com.br/JMA-index_noticias.asp?id=12606>. Acesso em: 09 mai. 2007.

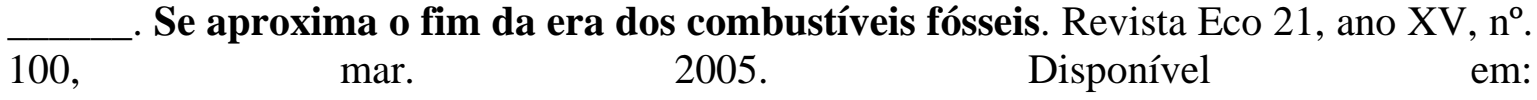
$<$ http://www.ambientebrasil.com.br/composer.php3?base=./energia/index.html\&conteudo= ./energia/artigos/seaproxima.html>. Acesso em: 22 ago. 2007.

; VASCONCELLOS, Gilberto Felisberto. Marxismo e biomassa. Revista Eco 21, Ano XIV, Edição 95, out. 2004. Disponível em: < http://www.eco21.com.br/textos/textos.asp?ID=880>. Acesso em: 23 jul. 2007.

ZANATTA, Mauro. Embrapa avaliará impacto ambiental de biocombustível. Disponível em: <http://agenciact.mct.gov.br/index.php/content/view/45476.html>. Acesso em: 03 set. 2007. 